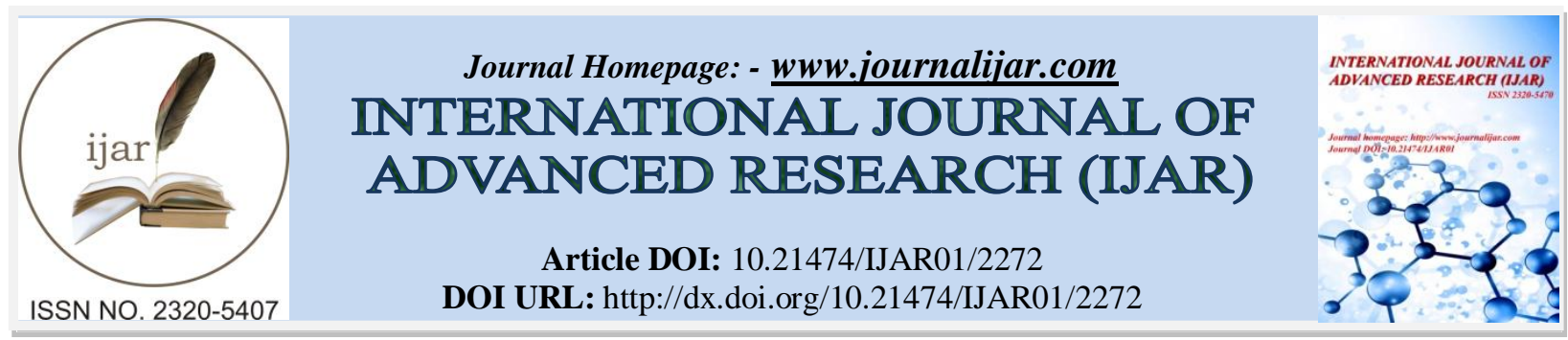

RESEARCH ARTICLE

\title{
IDENTIFICATION OF DIFFERENT LIVER DISEASES BY USING IMAGERY TECHNIQUES: A REVIEW.
}

\author{
Chetna Garg $^{1}$, Megha Bhadauria ${ }^{1}$, Saurabh Mukherjee ${ }^{2}$ and K. F. Rahman ${ }^{2}$. \\ 1. Mtech Scholar, Department of Computer Science, AIM \& ACT, Banasthali University, Rajasthan, India. \\ 2. Associate Professor, Department of Computer Science, AIM \& ACT, Banasthali University, Rajasthan, India.
}

\section{Manuscript Info}

Manuscript History

Received: 29 September 2016

Final Accepted: 30 October 2016

Published: November 2016

Key words:-

MRI, CT, ultrasound, Image pre-

processing, liver diseases.

\section{Abstract}

The aim of this study is to characterize the different liver diseases which are related to infect liver tissue and other infected part like spleen, pancreas, and stomach. The methods used are preprocessing ,segmentation, feature extraction, texture analysis which is depend upon the collection of Computed Tomography(CT) scans, MRI(Magnetic Resonance Imaging) and Ultrasounds(US) of different patient collected from the hospitals.

MRI is playing an important role in analyzing the liver disease patients due to its high soft tissue resolution, lack of ionizing radiation and ability to provide functional data. Imaging techniques like ultrasonography, CT scans, MRI are used to get the enhanced image of infected part of liver so that can easily characterized and detect the particular disease in liver patient. Diffusion Weighted Imaging (DWI) is used to identify the lesion in the liver and Perfusion Weighted Imaging (PWI) is used to identify the volume and functioning of the cirrhotic liver.

Copy Right, IJAR, 2016,. All rights reserved.

\section{Introduction:-}

Liver is the largest vital organ of our body located in the upper right quadrant of the abdomen, below the diaphragm which performs a wide range of functions including the removal of endogenous and exogenous material from the blood ,carbohydrate, homeostasis, detoxification of various metabolites, protein synthesis, urea function and immune functions .Liver could be involved by several serious diseases like fatty liver, cirrhosis ,hepatocellular carcinoma .Others can be the result of drugs, poisons or too much drinking of alcohol called fatty liver .If liver forms the scar tissue due to long duration of illness called cirrhosis and HCC develops in patients with chronic liver diseases .Classic symptoms of liver diseases such as nausea, vomiting, abdominal pain ,jaundice, fatigue so for detecting, diagnosis and monitoring these liver diseases apply the Invasive techniques which is used for diagnosis the abnormality in liver patient with the help of MRI, CT scans, ultrasound. MRI produces the 3D detailed anatomical images without use of damaging radiations. Often used for detect, diagnosis and treatment monitoring. CT scans is fast and painless use special $\mathrm{x}$-ray equipment and computers to produce the images and have more detailed information image then x-rays. Ultrasound uses sound waves to produce images of inside the body. It does not use ionizing radiation because it captures in real time and they can show the structure and movement of body internal organ. Liver diseases affect one in five Indians. People do not realize the liver disease in earlier but the critical condition can be converted in liver cancer.

Corresponding Author:- Chetna Garg.

Address:- Mtech Scholar, Department of Computer Science, AIM \& ACT, Banasthali University, Rajasthan, India. 


\section{Critical Analysis:-}

Francesco Agnello, Marco Dioguardi Burgio et al(2016)[1]: This paper describe the optimal MRI study protocol of the liver and the differences in stage of enhancement between cirrhotic and normal liver by using gadoxetic acid. Authors also illustrate the differences in steps of enhancement of between gadoxetic acid and extracellular contrast agents and they also discussed how to obtain and recognize an adequate hepatobiliary phase.

There are some merits and demerits of using gadoxetic acid.

- Using gadoxetic acid is higher hepatobiliary results in greater enhancement of liver parenchyma.

- Demerits of liver magnetic resonance imaging (MRI) with gadoxetic acid are the highest cost: the price of gadoxetic acid is almost twice that of gadobenate dimeglumine.

Mohamed E. M. Garelnabi, Mohammed A. Ali Omer et al(2016)[2]: In this review researchers, characterize and identify HCC using classification depending on the basis of disparity of grey level of plain, arterial and venous phases in CT images.

- Different important parameters have been considered for precise qualitative characterization of hepatic diseases like texture features, grey scale, fractal dimension estimators or shape descriptors, combined with a classifier.

Yoon Jin Lee, MD Jeong Min Lee et al(2015)[3]: This paper shows that MRI has higher overall per-lesion sensitivity extent than CT and can be more effectible with the use of hepatobiliary-specific MR contrast agents, even in challenging situations such are end-stage liver disease and lesions smaller than $1 \mathrm{~cm}$.

Ozum Tunçyurek, M. Onur Turkkan et al(2014)[4]: In this paper evaluated fibrosis and cirrhosis in cases with non alcoholic fatty liver disease by means of transient elastography and revealed that data equivalent to biopsy could be collected, that could not reach this result with the method of strain elastography.

Karthik Kalyan,Binal Jakhia et al(2014)[5]: In this study, five feature classifiers have been investigated for diagnosing the liver diseases. The accuracy of the classifier was based upon the feature set that has been used, selected training samples and classifier's ability to learn from the training samples. Five sets of features such as GLCM, GLRLM, intensity histogram, invariant moments, and mixed features were extracted.

Devendra Joshi ,Narendra D Londhe(2013)[6]: In this paper use adaptive thresholding technique for segmentation of liver tumor. Goal is to produce a technique in MATLAB for automatic segmentation by using DICOM images and it is processed and further converted in to jpeg images for segmentation. Authors use the thresholding technique in each slice for the segmentation of Tumour. This method effectively segments the Liver tumour when applied to abdominal CT images which is difficult to segment the tumour accurately.

Katia Passera, Sabrina Selvaggi et al(2013)[7]: This paper represents a first attempt to get a quantitative tool aimed to evaluate the accuracy of Radiofrequency ablation (RFA) treatment. The possibility to visualize the tumor and the correspondent post RFA necrosis in the exact same framework and the definition of some synthetic numerical indexes could help clinicians in ameliorating RFA treatment.

Hai-ying Zhou, Tian-wu Chen et al(2012)[8]: In this paper, the patterns and producing veins of the inflowing vessels of gastric fundic and esophageal varices were shown as correctly on CT-MPR images, which forward demonstrates the advantages of MDCT porto-graphy for evaluating varices.

Ming-Hong Hshiao,Po-Chou Chen et al(2012)[9]:This review paper describe that MRI is safe, fast, and noninvasive diagnostic techniques with high spatial resolution. In this review paper, a new concept dynamic gray level scaling and the filtering out of the artery and portal veins in the region of interest was successfully proceed to MRI of liver cirrhosis. The extracted features of the MRI T2-weigh-ted image give a quantitative measure of the extent of liver cirrhosis.

- Quantitative characters of standard deviation, mean, and entropy in the region of interest have been successfully calculated by the dynamic gray level scaling of T2-weighted MRI with high accuracy.

Marius George Linguraru, William J. Richbourg et al(2012)[10]: This paper brings together the automated segmentation of liver with detection, classification and segmentation of hepatictumors from typical clinical radiological data with variability in imaging acquisition parameters. The proposed method in this paper for the 
automated segmentation of the liver, and detection, segmentation, and classification of tumors can be employed as an assisting diagnostic tool robust to morphological changes from normal, pathological anatomical variability, as well as poor image quality or enhancement.

Frydrychowicz, MD,R. Landgraf et al(2011)[11]: This paper demonstrated the feasibility of performing comprehensive anatomic and hemody-namic visualization of hepatic and splanchnic blood flow with a single freebreathing acquisition. Hemodynamic visualization and vessel segmentation included color-coded three-dimensional (3D) streamlines and particle traces. Segmentation quality features was compared with contrast-enhanced multiphase liver imaging

- To analyze the hemodynamics with respect to visualization character and directionality to relate the image quality to the severity of the liver diseases as expressed by the survival rate following the MELD score [Models for End-stage Liver Disease].

- To underline the potential clinical impact by using presentation of case examples,

- Compared the vessel segmentation quality C-VIPR with contrast-enhanced liver imaging.

Li Wang, Jian-ping Lu(2011)[12]: This reviewed paper shows the 3D contrast-enhanced magnetic resonance angiography is non-invasive imaging techniques that can be completely visualize the hepatic vein, collateral circulation allowing clinicians and inferior vena cava to fully understand the disease before surgery is done. The use of MRA in BCS can potentially help to reduce surgical time and increase surgery success rates in the future.

A Furlan,MD,D Marin(2011)[13]: In this paper authors found, both liver parenchyma and HCC reached their maximum enhancement during the hepatic venous phase. Compared with the hepatic venous phase, the late phase yields a significantly higher detection rate of tumour washout at the time of multiphasic MDCT in patients with cirrhosis.

Nefise Cagla Tarhan, Tugce Hatipogu(2011)[14]: This paper determine whether the different vascularization patterns of HCC nodules observed at the time of three phases of dynamic liver MDCT correlate with histopathological differ-entiation grades.

Ricardo Ribeiro et al(2011) [15]: In this paper, study demonstrate that combining US liver contour features with laboratorial and clinical parameters can be useful for accurately identifying different stages of diffuse liver disease. Features extracted from the liver contour detected, as well as laboratorial features and clinical, can be used to train supervised classifiers to identify the disease.

Marius George Linguraru et al(2010) [16]: The results demonstrated the capability of the techniques to divide or segment the abnormal and normal liver, and spleens with a accuracy comparable to the inner observed variability and error close to the voxel size.

Young-sun Kim et al(2010) [17]: In this paper authors used image fusion and radial multiplanar reformation techniques for 3D analysis of ablative margins. The combination of both techniques enabled authors to evaluate the ablative margin according to quantity. The use of the radial multiplanar reformation technique made possible a complete examination in virtually every directions.

Katsutoshi Sugimoto et al(2010) [18]: Used micro-flow imaging (MFI) of contrast- enhanced ultrasound. Most of the methods, including transient US elastography, ), perfusion MRI, conventional US, double contrast material enhanced Magnetic Resonance Imaging(MRI), and diffusion MRI, are limited to the detection of advanced fibrosis. The image characteristics described on the MFI showed good correlation with the degree of liver fibrosis, and thus, the MFI of CEUS is useful for non-invasive staging fibrosis.

Luis Martí-Bonmat et al(2010) [19] : The typical histological features of cirrhosis influence and chronic hepatitis the appearance of liver and must be assessed separately by radiological imaging biomarkers in order to be useful clinically.

Behroze Vachha et al(2010) [20]: In this paper, authors found that

a. On ultrasound, hemorrhagic cysts seen as hypoechoic lesions with increased through transmission of sound and lack of internal vascularity, suggesting their cystic nature. 
b. On Computed Tomography, the main characteristic appearance is a very complex cystic lesion with variable features, which may range from cysts with more complex cystic masses with a thick well-defined fibrous capsule to internal hemorrhagic components, mural nodularity and internal septations. The appearance may show characteristics of biliary cystadenoma or biliary cystadeno carcinoma, but an infected, hemorrhagic cyst or effected does not show any enhancement in contrast

c. On MRI, the signal intensity varies depending on the contents of the complex cyst.

Magali sasso et al(2010) [21]: In this paper authors found that a novel ultrasonic controlled attenuation parameter (CAP) automatically estimates ultrasonic attenuation of the using a sophisticated guidance process .And authors also concluded that CAP is valid non invasive tool for steatosis detection and quantification.

Richard Allen et al(2010) [22]: Assessment of the liver surface using ultrasound consistently had moderate diagnostic correctness across many studies which exhibit good research methodology. Other techniques demonstrated variable or poor to better diagnostic accuracy. US of the liver surface is a useful diagnosing tool in patients at risk of Chronic Liver Disease while assessing whether they should undergo for a liver biopsy or not.

Hersh Chandaranaet al(2009)[23] : In this paper authors found that patients with iron deposition had shorter hepatic T2 values, than those patients without iron deposition (mean T2, $17.7 \mathrm{v} / \mathrm{s} 32.3$ milliseconds with pooled data from both two observer ; $p<0.0001$ ). Patient with iron grade 3 or more had lesser T2 values than those with iron grade 2 or minimum (10.1 v/s 20.8 millisecond; $p<0.0001)$. There was a strong negative correlation between hepatic T2 and histopathology iron grade $(r=-0.849 ; p<0.0001)$.

Tian-wu Chen et al(2009) [24]:In this papers authors found that with the development of MDCT, the acquisition of image has become increasingly faster so that high quality of Computed Tomography portography could be obtained to show the entire Porto systemic collaterals within the greater coverage along the $\mathrm{z}$-axis.

Maha Torabi et al(2008) [25]: In this paper authors found that some lesions components remains hypoattenuating in arterial, portal venous, and delayed phase, representing regions of necrotic tissue, hemorrhage, or fibrous tissue with little or no vascularization seen at histologic analysis.

Meng Yin et al(2007) [26]: In this paper authors found that liver stiffness increases systematically with the stage of fibrosis. Also demonstrated that Receiver operating curve (ROC) analysis with a shear stiffness cut off value of 2.93 $\mathrm{kPa}$, the estimated specificity and sensitivity for detecting all grades of liver fibrosis is $98 \%$ and $99 \%$.

Giuseppe Brancatelli et al(2006) [27]: This paper demonstrate that both CT and MR provide valuable deep understanding into the extent of hepatic injury from complications and cirrhosis including portal hypertension.

Motoh Iwasa et al(2005) [28]:This study demonstrated that there are many patients with abnormalities in the anterior cingulate gyrus in the Liver Cirrhosis group particularly, they showed significant decrease in blood flow in the anterior cingulate gyrus and in the frontal lobes.

Nader Binesh et al(2005) [29]: MR spectroscopic results showed a statistically significant decrease in choline (Ch) and myo-inositol (mI) and an increase in glutamate/glutamine (Glx) in patients when compared to healthy controls

Sherif Saadeh et al(2002) [30]:This study indicates that the condition of being severe of hepatic steatosis can be correctly decide radiological imaging only when there is severe (33\%) or moderate fatty infiltration of the liver documented by a liver biopsy.

Paola Di Giacomoa, Giovanni Felicib et al(2001)[31]In this review paper authors described that the application of new learning tool for the diagnosis the hepatocellular carcinoma. This method presents the several interesting features of medical diagnosis system. 
Table 1:- Imagery techniques used during 2001-2016 for detection of liver diseases

\begin{tabular}{|c|c|c|}
\hline Authors' Name & Techniques Used & Critical Remarks \\
\hline $\begin{array}{ll}\text { Francesco } & \text { Agnelo } \\
\text { al }(2016)[1] & \end{array}$ & $\begin{array}{l}\text { Gadoxetic Acid, Magnetic resonance } \\
\text { imaging }\end{array}$ & $\begin{array}{l}\text { Radiologists involved in liver imaging } \\
\text { need to be familiar with the state-of-art } \\
\text { MRI study protocol of the liver and the } \\
\text { special characteristics of gadoxetic } \\
\text { acid. }\end{array}$ \\
\hline $\begin{array}{l}\text { Mohamed E. M. Garelnabi et } \\
\text { al(2016)[2] }\end{array}$ & Texture Analysis, K-means & $\begin{array}{l}\text { Some HCCs, especially small or well- } \\
\text { differentiated lesions, may not be } \\
\text { hyper-enhancing on arterial phase } \\
\text { images, only } 58 \% \text { of HCCs }<2 \mathrm{~cm} \\
\text { were hyper-vascular on the arterial } \\
\text { phase }\end{array}$ \\
\hline Yoon Jin Lee et al(2015)[3] & Magnetic Resonance Imaging (MRI) & $\begin{array}{l}\text { MRI showed higher per-lesion } \\
\text { sensitivity than multi-detector CT and } \\
\text { should be tend to choose imaging } \\
\text { modality for the diagnosis of HCCs in } \\
\text { patients. }\end{array}$ \\
\hline $\begin{array}{l}\text { Ozum Tunçyurek et } \\
\text { al(2014)[4] }\end{array}$ & Elastography, hepatosteatosis, ultrasound & $\begin{array}{l}\text { elastography technique failed to clearly } \\
\text { differentiate between the degrees of } \\
\text { hepatosteatosis, which could be } \\
\text { differentiated by B-mode Ultrasound. }\end{array}$ \\
\hline Karthik Kalyan et al(2014)[5] & $\begin{array}{l}\text { Image-Processing , Ultrasound, GLRLM, } \\
\text { Neural Network }\end{array}$ & $\begin{array}{l}\text { GLRLM and mixed feature set showed } \\
\text { excellent accuracy in training as well } \\
\text { as testing. }\end{array}$ \\
\hline Devendra Joshi et al(2013)[6] & $\begin{array}{l}\text { Automatic segmentation, Adaptive } \\
\text { thresholding, Boundaries ,region splitting } \\
\text { and merging. }\end{array}$ & $\begin{array}{l}\text { The proposed segmentation } \\
\text { method improves the Segmentation } \\
\text { performance } \\
\text { compared with the conventional } \\
\text { process based on a regular gray value }\end{array}$ \\
\hline Katia Passeral et al(2013)[7] & $\begin{array}{l}\text { Image Processing ,Radiofrequency ablation } \\
\text { (RFA), Fuzzy-C-Means approach }\end{array}$ & $\begin{array}{l}\text { The performance will be slighter lower } \\
\text { then when larger dataset of unseen data } \\
\text { are considered }\end{array}$ \\
\hline Hai-ying Zhou et al(2012)[8] & MDCT & $\begin{array}{l}\text { The diameter of the splenic vein can be } \\
\text { used to predict esophageal and gastric } \\
\text { fundic varices and their patterns. }\end{array}$ \\
\hline $\begin{array}{l}\text { Ming-Hong Hshiao } \\
\operatorname{al}(2012)[9]\end{array}$ & Image-processing, MRI & $\begin{array}{l}\text { AUC is a widely used measure of } \\
\text { accuracy of classification. Higher } \\
\text { values of AUC indicate classification, } \\
\text { AUC values of SD, mean, and entropy } \\
\text { all exceeded } 93 \%(P<0.001) \text {. }\end{array}$ \\
\hline $\begin{array}{l}\text { Marius George Linguraru et } \\
\text { al(2012)[10] }\end{array}$ & $\begin{array}{l}\text { contrast-enhanced computed tomography } \\
\text { (CT), parameterization, segmentation, } \\
\text { shape. }\end{array}$ & $\begin{array}{l}\text { Technique improved significantly the } \\
\text { segmentation of cases with large } \\
\text { tumors and segmentation } \\
\text { errors }(\mathrm{P}<.001)\end{array}$ \\
\hline Frydrychowicz et al(2011)[11] & $\begin{array}{l}\text { Phase contrast imaging; velocity mapping; } \\
\text { flow-sensitive MRI }\end{array}$ & $\begin{array}{l}\text { Models for End-stage Liver Disease( } \\
\text { MELD score) score may not } \\
\text { necessarily reflect the severity of portal } \\
\text { hypertension itself }\end{array}$ \\
\hline Li Wang et al(2011)[12] & $\begin{array}{l}\text { Magnetic resonance angiography-Image } \\
\text { processing }\end{array}$ & $\begin{array}{l}\text { When magnetic resonance angiography } \\
\text { shows that the } \\
\text { occlusion of the inferior vena cava is } \\
\text { near to the right atrium, it is not } \\
\text { suitable to puncture the jugular vein. }\end{array}$ \\
\hline A Furlan et al(2011)[13] & (Multidetector & Diagnosis of HCC at contrast-enhanced \\
\hline
\end{tabular}




\begin{tabular}{|c|c|c|}
\hline & Tomography) & $\begin{array}{l}\text { MDCT requires the existence of } \\
\text { nodule hypervascularity and venous } \\
\text { washout are demonstrated }\end{array}$ \\
\hline $\begin{array}{l}\text { Nefise Çagla Tarhan et } \\
\text { al(2011)[14] }\end{array}$ & Computed Tomography, spiral computed & $\begin{array}{l}\text { Conventional angiography is } \\
\text { considered to be the gold Standard for } \\
\text { demonstrating the vascularity of HCC } \\
\text { lesions }\end{array}$ \\
\hline $\begin{array}{l}\text { Ricardo Ribeiro et al(2011) } \\
{[15]}\end{array}$ & Used Ultrasound Imaging & $\begin{array}{l}\text { Combining features further improves } \\
\text { the classifiers performance. }\end{array}$ \\
\hline $\begin{array}{l}\text { Marius George Linguraru et } \\
\text { al(2010) [16] }\end{array}$ & Used Computed Tomography & $\begin{array}{l}\text { Segmentation can still suffer from } \\
\text { errors induced by adjacent organs, } \\
\text { partial volume effects and variations in } \\
\text { contrast in-take during enhancement. }\end{array}$ \\
\hline $\begin{array}{l}\text { Young-sun Kim et al(2010) } \\
\text { [17] }\end{array}$ & $\begin{array}{l}\text { Used CT scans and fusion, and image } \\
\text { fusion or radial multiplanar }\end{array}$ & $\begin{array}{l}\text { If image fusion or radial multiplanar } \\
\text { reformation technique is unavailable } \\
\text {,utilization of either technique - for } \\
\text { instance image fusion of conventional } \\
\text { coronal or sagittal maultiplanar- can be } \\
\text { used. }\end{array}$ \\
\hline $\begin{array}{l}\text { Katsutoshi } \begin{array}{l}\text { Sugimoto } \\
\text { al(2010) [18] }\end{array} \\
\text { et }\end{array}$ & $\begin{array}{lr}\text { Contrast-enhanced } & \text { ultrasound } \\
\text { (CEUS);CEUS with } & \text { MFI(micro-flow } \\
\text { imaging) has been used. } & \end{array}$ & $\begin{array}{l}\text { The MFI of CEUS is useful for non- } \\
\text { invasive staging fibrosis. }\end{array}$ \\
\hline $\begin{array}{ll}\text { Luis Martí-Bonmati et } \\
\text { al(2010) [19] }\end{array}$ & Used Magnetic Resonance Imaging & $\begin{array}{l}\text { A biopsy is not necessary if clinical } \\
\text { and radiological data suggest cirrhosis }\end{array}$ \\
\hline $\begin{array}{l}\text { Behroze Vachha et al(2010) } \\
\text { [20] }\end{array}$ & $\begin{array}{l}\text { Using CT scans, MRI and Ultrasounds for } \\
\text { liver cysts }\end{array}$ & $\begin{array}{lcr}\text { Imaging } & \text { characteristics } & \text { cannot } \\
\text { definitely distinguish } & \text { biliary } \\
\text { cystadenoma } & \text { from } & \text { biliary } \\
\text { cystadenocarcinoma. Therefore, the } \\
\text { optimal management of these masses is } \\
\text { surgical resection. }\end{array}$ \\
\hline Magali sasso et al(2010) [21] & $\begin{array}{l}\text { Using ultrasonic controlled attenuation } \\
\text { parameter (CAP); CAP is a noninvasive, } \\
\text { immediate, objective and efficient method } \\
\text { to detect and quantify steatosis. }\end{array}$ & $\begin{array}{l}\text { CAP automatically estimates the } \\
\text { ultrasonic attenuation of the liver using } \\
\text { a sophisticated guidance process. CAP } \\
\text { is actually an estimate of the ultrasonic } \\
\text { attenuation at } 3.5 \mathrm{MHz} \text {. }\end{array}$ \\
\hline Richard Allen et al(2010) [22] & $\begin{array}{l}\text { Using Ultrasound Imaging for Cystic Liver } \\
\text { Disease(CLD) }\end{array}$ & $\begin{array}{l}\text { Paper research was restricted to } \\
\text { ultrasound images only. Ultrasound of } \\
\text { the liver surface is a useful diagnostic } \\
\text { tool in patients at risk of CLD when } \\
\text { assessing whether they should undergo } \\
\text { a liver biopsy or not. }\end{array}$ \\
\hline $\begin{array}{ll}\text { Hersh } & \text { Chandaranaet } \\
\text { al(2009)[23] } & \end{array}$ & $\begin{array}{l}\text { Used MRI sequence in the detection and } \\
\text { quantification of hepatic iron deposition in } \\
\text { patients with liver disease. }\end{array}$ & $\begin{array}{l}\text { MRI with hepatic T2 measured within } \\
\text { a breath hold have excellent sensitivity } \\
\text { and specificity in the diagnosis of the } \\
\text { presence of and quantification of } \\
\text { hepatic iron }\end{array}$ \\
\hline Tian-wu Chen et al(2009) [24] & $\begin{array}{l}\text { Used 64-row Multidetector Computed } \\
\text { Tomography (MDCT). }\end{array}$ & $\begin{array}{l}\text { Multidetector CT overcomes the } \\
\text { limitations of conventional spiral CT } \\
\text { because its data acquisition is several } \\
\text { times faster than with conventional } \\
\text { helical CT scanners. }\end{array}$ \\
\hline Maha Torabi et al(2008) [25] & $\begin{array}{l}\text { Used Multiphase } \\
\text { tomography }(\mathrm{CT})\end{array}$ & $\begin{array}{l}\text { Multiphase helical computed } \\
\text { tomography (CT) allows evaluation of } \\
\text { the liver during both the arterial and the } \\
\text { portal venous phases of contrast }\end{array}$ \\
\hline
\end{tabular}




\begin{tabular}{|c|c|c|}
\hline & & $\begin{array}{l}\text { enhancement and therefore is an } \\
\text { important modality for the detection } \\
\text { and characterization of hepatic } \\
\text { neoplasms. }\end{array}$ \\
\hline Meng Yin et al(2007) [26] & $\begin{array}{l}\text { Used Magnetic Resonance Elastography } \\
\text { (MRE) for detecting liver fibrosis }\end{array}$ & $\begin{array}{l}\text { MRE is a safe, non-invasive technique } \\
\text { with excellent diagnostic accuracy for } \\
\text { assessing hepatic fibrosis. }\end{array}$ \\
\hline $\begin{array}{l}\text { Giuseppe Brancatelli et } \\
\text { al(2006) [27] }\end{array}$ & $\begin{array}{l}\text { Used Magnetic Resonance Imaging(MRI) } \\
\text { and Computed Tomography(CT) }\end{array}$ & $\begin{array}{l}\mathrm{CT} \text { and } \mathrm{MR} \text { are quite accurate } \\
\text { in detection and characterization of } \\
\text { larger }(>2 \mathrm{~cm}) \text { lesions, }\end{array}$ \\
\hline Motoh Iwasa et al(2005) [28] & $\begin{array}{l}\text { Used Single Photon Emission Computed } \\
\text { Tomography (SPECT) }\end{array}$ & $\begin{array}{l}\text { Reduced blood flow in the anterior } \\
\text { cingulate gyrus is frequently observed } \\
\text { in Liver Cirrhosis (LC) patients. }\end{array}$ \\
\hline Nader Binesh et al(2005) [29] & $\begin{array}{l}\text { Magnetic resonance spectroscopy (MRS) } \\
\text { has been used }\end{array}$ & $\begin{array}{l}\text { Demonstrated the feasibility of } \\
\text { evaluating the two-dimensional L- } \\
\text { COSY (Correlated Magnetic } \\
\text { Resonance Spectroscopic) sequence in } \\
\text { a clinical environment. }\end{array}$ \\
\hline Sherif Saadeh et al(2002) [30] & $\begin{array}{l}\text { Used Ultrasonography (US), computerized } \\
\text { tomography (CT), and magnetic resonance } \\
\text { imaging (MRI). }\end{array}$ & $\begin{array}{l}\text { Radiological modalities are unable to } \\
\text { distinguish between NASH } \\
\text { (nonalcoholic steatohepatitis) and other } \\
\text { forms of NAFLD (nonalcoholic fatty } \\
\text { liver disease) }\end{array}$ \\
\hline $\begin{array}{lccc}\text { Paola } & \text { Di } & \text { Giacomoa } & \text { et } \\
\text { al(2001)[31] } & & \end{array}$ & $\begin{array}{l}\text { Supervised learning, } \\
\text { ultrasounds,Lsquare }\end{array}$ & $\begin{array}{l}\text { In future error distribution can be } \\
\text { reduced by establishing the new } \\
\text { confidence level of diagnosis. }\end{array}$ \\
\hline
\end{tabular}

\section{Conclusion and Future Scope:-}

Through this study we got to know about several Liver disease and how these diseases can be detect radiologically. We found that HCC(Hepatocellular Carcinoma), Cirrhosis, FLD (Fatty Liver Disease) and NAFLD (Non Alcoholic Fatty Liver Disease) are the most common liver diseases. The most common Imagery technique to detect these diseases is CT(Computed Tomography. MRI (Magnetic Resonance Imaging) is mostly used for the diagnosis of tumor development because of its ability to reliably depict HCC. And Ultrasound (US) is the best way for detecting cystic appearance in Liver.

We can enhance the quality of CT images by using HRCT (High Resolution CT). We can try to detect lesions less than $2 \mathrm{~cm}$ in size using MRI and CT.

\section{Acknowledgement:-}

This research paper is supported by Dean G.N. Purohit of AIM \& ACT Department, Banasthali University, for providing the opportunity to carry out our 10 months internship from Banasthali University.

\section{Referrences:-}

1. Francesco Agnello, Marco Dioguardi Burgio, Dario Picone, Federica Vernuccio and Giuseppe Cabibbo," Magnetic resonance imaging of chirrhotic liver in the era of gadoxetic acid", World Journal of Gastroenterology , January 7, 2016

2. Mohamed E. M. Garelnabi1, Mohammed A. Ali Omer1,2, Samia A. Fathelrahman3 and Albosairi T. Ahmed3," Characterization of Hepatocellular Carcinoma Using CT Intensity and K-means", International Journal of Science and Research (IJSR), Volume 5, January 1, 2016

3. Yoon Jin Lee, MD Jeong Min Lee, MD Ji Sung Lee, PhD Hwa Young Lee, MS Bo Hyun Park, PhD Young Hoon Kim, MD Joon Koo Han and MD Byung Ihn Choi, MD ," Diagnostic Performance of Multidetector CT and MR Imaging-A Review and Meta-Analysis1",Volume 275,April1, 2015 
4. Ozum Tunçyurek, M. Onur Turkkan, Nalan Mirzai, Uğur Açıkalın and Pars Tunçyürek," Ultrasound Elastography Findings in Patients with NAFLD", Journal of Adnan Menderes University Medical Faculty,September 18,2014

5. Karthik Kalyan,1Binal Jakhia,1 Ramachandra Dattatraya Lele,2,3Mukund Joshi,4 and Abhay Chowdhary," Artificial Neural Network Application in the Diagnosis of Disease Conditions with Liver Ultrasound Images", Advances in Bioinformatics, September 16, 2014

6. Devendra Joshiland Narendra D Londhe " Automatic Liver Tumour Detection in Abdominal CT Images", International Journal of Computer Technology and Electronics Engineering(IJCTEE)Volume3, Issue1, February 2013

7. Katia Passera, Sabrina Selvaggi, Davide Scaramuzza, Francesco Garbagnati3, Daniele Vergnaghi and Luca Mainardi," Radiofrequency ablation of liver tumors: quantitative assessment of tumor coverage through CT image processing", BMC Medical Imaging,2013

8. Hai-ying Zhou, Tian-wu Chen, Xiao-ming Zhang, Li-ying Wang, Li Zhou, Guo-li Dong, Nan-lin Zeng, Hang $\mathrm{Li}$,Xiao-li Chen and Rui $\mathrm{Li}$," The diameter of the originating vein determines esophageal and gastric fundic varices in portal hypertension secondary to posthepatitic cirrhosis", CLINICS, 2012

9. Ming-Hong Hshiao,1, 2, 3Po-Chou Chen,4Jo-Chi Jao,5Yung-Hui Huang,2Chen-Chang Lee,1Shih-Yu Chao,1Li-Wei Lin and Tai-Been Chen2," Quantifying Liver Cirrhosis by Extracting Significant Features from MRI T2 Image", The Scientific World Journa,l Volume 2012

10. Marius George Linguraru*, William J. Richbourg, Jianfei Liu, Jeremy M. Watt, Vivek Pamulapati,Shijun Wang, and Ronald M. Summers," Tumor Burden Analysis on Computed Tomography by Automated Liver and Tumor Segmentation",IEEE TRANSACTIONS ON MEDICAL IMAGING, VOL. 31, NO. 10, OCTOBER 2012

11. Frydrychowicz, MD,1B.R. Landgraf, BS,1E. Niespodzany, MS,1,2R.W. Verma, MD,1A. Roldá n-Alzate, PhD and 1K.M. Johnson," Four-Dimensional Velocity Mapping of the Hepatic and Splanchnic Vasculature With Radial Sampling at 3 Tesla: A Feasibility Study in Portal Hypertension", Journal of Magnetic Resonance Imaging,June 7,2011

12. Li Wang, Jian-ping Lu, Fei Wang, Qi Liu, Jian Wang," Diagnosis of Budd-Chiari syndrome: three-dimensional dynamic contrast enhanced magnetic resonance angiography”, Springer Science+Business Media, March 12, 2011

13. A Furlan,MD,D Marin," Hepatocellular carcinoma in cirrhotic patients at multidetector CT: hepatic venous phase versus delayed phase for the detection of tumour washout", The British Journal of Radiology, 2011

14. Nefise Çağla Tarhan, Tuğçe Hatipoğu, Eylül Ercan, Merve Bener, Göksun Keleş Ceyla Başaran and Banu Bilezikçi ," Correlation of dynamic multidetector CT findings with pathological grades of hepatocellular carcinoma", Diagn Interv Radiology,February 15,2011.

15. Ricardo Ribeiro, Rui Marinho and Jose Velosa , "Diffuse Liver Disease Classification from Ultrasound Surface Characterization", Clinical and Laboratorial Data, Jr. Department of Gastroenterology and Hepatology, 2011.

16. Marius George Linguraru, Jesse K. Sandberg, Zhixi Li, Furhawn Shah, and Ronald M. Summers, “ Automated segmentation and quantification of liver and spleen from CT images" using normalized probabilistic atlases and enhancement estimation, Medical Physics: The International Journal of Medical Physics Research and Practice, 2010.

17. Young-sun Kim, Won Jae Lee, Hyunchul Rhim, Hyo K. Lim, Dongil Choi, Ji Young Lee, "The Minimal Ablative Margin of Radiofrequency Ablation of Hepatocellular Carcinoma ( $>2$ and $<5 \mathrm{~cm}$ ) Needed to Prevent Local Tumor Progression: 3D Quantitative Assessment Using CT Image Fusion” Vascular and Interventional Radiology-Original Research, 2010.

18. Katsutoshi Sugimoto, Junji Shiraishi, Fuminori Moriyasu, Shigeki Ichimura, Ryo Metoki and Kunio Doi, "Analysis of intrahepatic vascular morphological changes of chronic liver disease for assessment of liver fibrosis stages by micro-flow imaging with contrast-enhanced ultrasound: preliminary experience", European Society of Radiology, 2010.

19. Luis Marti-Bonmati and Fructuoso Delgado "MR imaging in liver cirrhosis: classical and new approaches", Springer, 2010.

20. Behroze Vachha, Maryellen R. M. Sun, Bettina Siewert and Ronald L. Eisenberg, "Cystic Lesions of the Liver", American Roentgen Ray Society, 2010.

21. Magali Sasso, Michel Beaugrand, Y. Victor De Ledinghen, Catherine Douvin, Patrick Marcellin, Raoul Poupon, Laurent Sandrin and Ve Ronique Miette, “Controlled Attenuation Parameter(CAP): A Novel VCTE 
Guuided Ultrasonic Attenuation Measurement Study and Validation in a Cohort of Patients with Chronic liver Disease from various causes", Elsevier, 2010.

22. Richard Allan, Kerry Thoirs and Maureen Phillips, "Accuracy of ultrasound to identify chronic liver disease", World Journal of Gastroenterology,2010.

23. Hersh Chandarana, Ruth P. Lim, Jens H. Jensen, Cristina H. Hajdu, Mariela Losada, James S. Babb, Steve Huffman and Bachir Taouli, "Hepatic Iron Deposition in PatientsWith Liver Disease: Preliminary Experience With Breath-Hold Multiecho T2-Weighted Sequence", American Roentgen Ray Society; AJR, 2009.

24. Tian-wu Chen, Zhi-gang Yang, Xiao Li, Qi-ling Wang, Ling-ling Qian and Rui-rong Wang, "Evaluation of entire gastric fundic and esophageal varices secondary to posthepatitic cirrhosis: portal venography using 64row MDCT", Springer Science+Business Media,2009.

25. Maha Torabi,Keyanoosh Hosseinzadeh and Michael P. Federle, "CT of Nonneoplastic Hepatic Vascular and Perfusion Disorders", RSNA Available: radiographics.rsnajnls.org, 2008.

26. Meng Yin, Jayant A. Talwalkar, Kevin J. Glaser, Armando Manduca, Roger C. Grimm, Phillip J. Rossman, Jeff L. Fidler, and Richard L. Ehman, " A Preliminary Assessment of Hepatic Fibrosis with Magnetic Resonance Elastography”, NIH Public Access: Clin Gastroenterol Hepatol, 2007.

27. Giuseppe Brancatelli, Michael P. Federle, Roberta Ambrosini , Roberto Lagalla, Alessandro Carriero , Massimo Midiri and Valerie Vilgrain, "Cirrhosis: CT and MR imaging evaluation, European Journal of Radiology", Elsevier, 2006.

28. Motoh Iwasa, Kaname Matsumura, Yuri Nakagawa,Mika Yamamoto,Hideaki Tanaka, Shinichiro Horiike, Jiro Ikoma, Masahiko Kaito, Kan Takeda, and Yukihiko Adachi, "Evaluation of Cingulate Gyrus Blood Flow in Patients With Liver Cirrhosis", Springer Science+Business Media,2005.

29. Nader Binesh, Mir Huda, Mary Bugbee, Rakesh Gupta, Natalie Rasgon, Anand Kumar, Michael Green, Steven Han, and M. Albert Thomas, "Adding Another Spectral Dimension to 1H Magnetic Resonance Spectroscopy of Hepatic Encephalopathy”, Journal of Magnetic Resonance Imaging, 2005.

30. Shrif Saadeh, Zobair M. Younossi, Erick M. Remer,Terry Gramlich, Janus P. Ong, Maja Hurley, Kevin D. Mullen, James N. Cooper and Michhael J. Sheridan, "The Utility of Radiological Imaging in Nonalcoholic Fatty Liver Disease", Radiological Imaging Modalities and NAFLD, 2002.

31. Paola Di Giacomoa, Giovanni Felicib, Riccardo Maceratinic and Klaus Truemper," Application of a new logic domain method for the diagnosis of hepatocellular carcinoma",2001. 